Alma Mater Studiorum - Università di Bologna DEPARTMENT OF ECONOMICS

\title{
Populism and Institutional Capture
}

Nicholas Chesterley

Paolo Roberti

Quaderni - Working Paper DSE N०1086

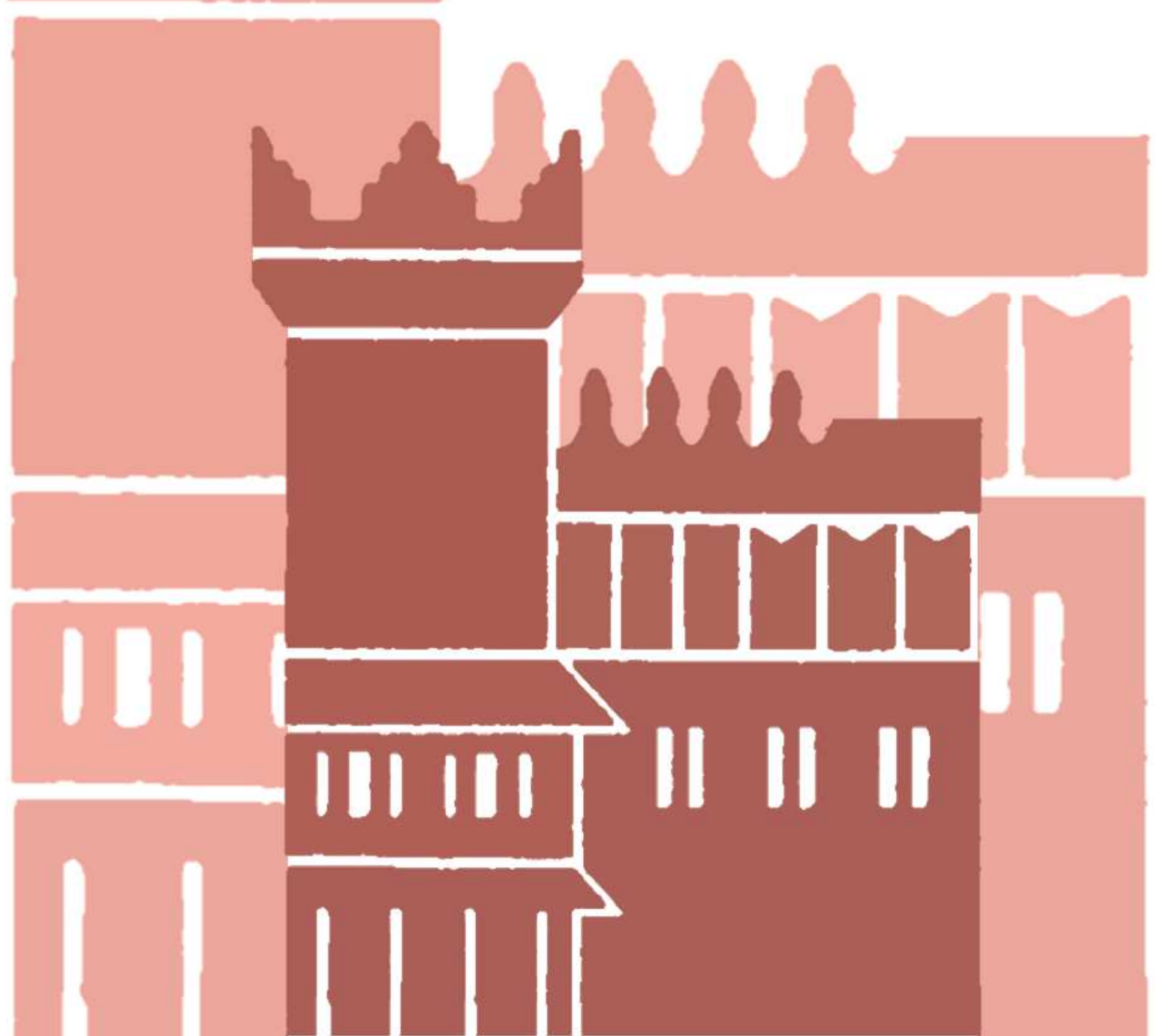




\title{
Populism and Institutional Capture*
}

\author{
Nicholas Chesterley \\ Oxford University
}

\author{
Paolo Roberti ${ }^{\dagger}$ \\ University of Bologna
}

October 18, 2016

\begin{abstract}
This paper considers electoral behavior and institutional capture when voters choose between a populist and non-populist politician. Populist politicians provide voters with a utility boom followed by a subsequent bust, as in Dornbusch and Edwards (The Macroeconomics of Populism in Latin America, University of Chicago Press, 1991). Non-populists provide a constant level of utility. Once in power, however, politicians of both types are able to seize control of institutions to ensure their re-election. We show that in equilibrium, populist politicians may capture institutions to avoid being replaced during the bust: non-populists do not. Voters rationally elect a populist if voters discount the future sufficiently or if it is too costly for the populist to seize control of institutions. Unfortunately, both types of politician may prefer weakened institutions, either to allow their capture or to discourage the election of the populist.
\end{abstract}

JEL-Classication: D72, D73, D74

Keywords: voting; populism; capture

\section{Introduction}

Populism is widely recognized as a striking political phenomenon of the early 21st century, though it is also difficult to define. The term typically pools

*Acknowledgements: the authors thank Massimo Morelli, Matthew Ellman, Antonio Nicolò, Andrea Mattozzi, Elena Lucchese and all the participants of the Sixth Workshop on Institutions, Individual Behaviour and Economic Outcomes in Alghero, Italy, and the seminar in University of Modena and Reggio Emilia, Modena, Italy, for helpful comments and suggestions.

${ }^{\dagger}$ Corresponding author. Email address: paolo.roberti3@unibo.it 
together figures as disparate as Chavez, Cristina Fernandez, Berlusconi, and Putin, as well as movements such as Front National in France or Movimento 5 Stelle in Italy. Political scientists often analyze populism through the contrast between a Marxist discourse and a populist one (Mudde (2004), Mény and Surel (2002)). While Marxist rhetoric refers to a struggle between classes, populist rhetoric underlines the contrast between the people as a whole and a corrupt elite.

Dornbusch and Edwards (1991) look at the economic content of populist proposals, and conclude that populism presents easy solutions to complex problems, which can be welfare enhancing in the short term but costly in the long run. This view is shared by Sachs (1989), who calls this type of dynamics "the populist policy cycle". A recent example is Venezuela under Chavez, where redistributive policies paired with imprudent fiscal behavior led after a few years to spiralling inflation and put the country on the verge of collapse. ${ }^{1}$ Argentina experienced a similar outcome under Fernandez's presidency.

The long-term economic effects of populist policies analyzed by Dornbusch and Edwards (1991) is at odds with the persistence in office that populist leaders seem to have enjoyed in recent years, and suggests the use of some kind of incumbent advantage to preserve their power. The key aim of this paper is to understand if populist politicians have a larger incentive to take actions aimed at remaining in office despite the will of voters, and to study the incentives for voters to elect politicians who may then attempt such a capture.

A wide literature shows that ruling politicians have at their disposal an array of tools to ensure their re-election. The most straightforward is a change of electoral rules: Boix (1999) looks at the history of democracies in the developed world and shows that electoral systems have been strategically changed in order to favor the incumbent. More recently, Chavez, Putin and Berlusconi have all been accused of changing electoral rules in a way that favored their re-election. Politicians can also pursue gerrymandering, redrawing electoral districts in order to increase the representation of the incumbent's party (Friedman and Holden (2008)), or even consider electoral fraud, an illegal effort to shape election results (Lehoucq (2003)). Another commonly-used tool to make re-election of an incumbent more likely is media capture, discussed in Prat and Stromberg (2013). If the government supresses independent media or takes direct control of state-owned media, it can influence voters' decisions through the selection of the information they

\footnotetext{
${ }^{1}$ See http://www.theguardian.com/world/2016/jan/16/venezuela-president-declareseconomic-emergency-as-inflation-hits-141
} 
receive. ${ }^{2}$ In Italy, for example, it is often suggested that Berlusconi's control over the media helped perpetuate his power, while in 2009 Venezuela's Chavez was accused of revoking the licenses of 34 radio stations and the largest TV station in the country in an effort to control the media and make his re-election more likely. Similar links have been suggested between Putin in Russia, Fujimori in Peru, Fernandez in Argentina and their respective media (Enikolopov et al. (2011), McMillan and Zoido (2004)).

In order to encompass all these different cases, we define by institutional capture any action that can be performed only by an incumbent politician which increases her re-election probability, despite the will of voters. We adopt one stylized fact about populism: that as in Dornbusch and Edwards (1991), the effect of populism on welfare is positive in the short term, but negative in the long-run. We find that populist politicians are particularly likely to seize control of institutions because voters would like to replace them when the costs of their policies take effect. Non-populists, in contrast, do not need to capture institutions because they offer a consistent level of utility in each period. Voters therefore face an identical choice in every election. If a non-populist has been elected and is in a position of incumbency, then ceteris paribus the voters will choose to re-elect her in the subsequent period, and so there is no incentive for institutional capture.

Whether populist leaders are elected or not depends on two fundamental factors: how much voters care about the future as opposed to the present, and the resilience of institutions to capture by the government. If voters highly discount the future, they elect a populist and disregard the long-term consequences of populist policies. If voters care sufficiently about the future, however, then they will be willing to elect a populist only if institutions are hard to capture (thus making institutional capture by the populist too costly for the populist). If voters place a particularly high value on future returns, voters always prefer to elect a non-populist.

These results on voter behavior can help us analyze populism worldwide. We suggest that societies with relatively impatient voters can be expected to experience populism. Moreover, if in these societies institutions are easy to capture, populism is likely to persist. Research has suggested Latin American countries demonstrate both of these traits, and indeed populism has been a relatively wide and persistent feature of Latin American politics. ${ }^{3}$ In

\footnotetext{
${ }^{2}$ This strategy works even if voters are rational and know that they are being fed selected information, as in Kamenica and Gentzkow (2011).

${ }^{3}$ Falk et al. (2015) analyze the distribution of patience across countries and show Latin American countries to be on average relatively impatient. Institutional resilience, measured as 'constraints on the executive', has also been suggested to be historically low in these countries, as in Acemoglu and Robinson (2001).
} 
contrast, our results suggest that countries with similar level of patience but stronger institutions might also be willing to elect populists but will see them struggle to seize institutions and so demonstrate less persistence. Italy under Berlusconi might be an example of this second case: many of the institutional changes taken place under his government aimed at increasing his political power have been ruled uncostitutional by independent judges, reducing his ability to stay in office.

The analysis on populism is in some sense comparable to other contexts of intertemporal choice and addiction, such as Becker and Murphy (1988). Voters may rationally choose to become 'addicted' to populist politicians, electing them despite the subsequent institutional capture. Having chosen to vote for them because of the short-term rewards, however, they are then unable to quit, because of the populists' capture of institutions.

Unfortunately, we also find that politicians have little incentive to increase institutional resilience to capture. When facing impatient voters, populist leaders are always elected. Thus they would like institutions to be as vulnerable as possible to capture, to reduce the costs of seizing them. If voters are less impatient, the non-populist would like institutions to be sufficiently vulnerable that the electorate prefers not electing the populist at all, until for sufficiently patient voters, the non-populist is always elected and so is indifferent to institutional resilience. Somewhat counterintuitively, only populists ever have an incentive to increase institutional resilience, and then only in order to convince voters with an intermediate level of impatience that they will not be able to seize power and so are worth electing.

Our work can be compared to the analysis on populism performed by Acemoglu et al. (2013a), which is also inspired by the definition of macroeconomic populism of Dornbusch and Edwards (1991). Acemoglu et al. (2013a) denote populism "as the implementation of policies receiving support from a significant fraction of the population, but ultimately hurting the economic interests of this majority", and operationalize this definition as a policy left of the median voter, studying the incentives for the implementation of populist policies on a ideological line. ${ }^{4}$ A similar approach is used by Leon (2014) and Mejía and Posada (2007), who relate the emergence of populism with the risk of military repression. Rather than looking at the ideological dimension, our model focuses on the dynamic feature of populism, which trades off a boom in the present for a bust in the future.

Our approach is also related to the literature on captured democracies,

\footnotetext{
${ }^{4}$ In their work, as in Frisell (2009), politicians adopt populist policies to signal that they do not pander to lobbies. In Binswanger and Prüfer (2012) politicians are defined as populist if they pander to voters' opinion, despite having superior information. They show that the incentive to pander is affected by voters' limited strategic sophistication.
} 
where elites take control of weakly institutionalized States (Acemoglu and Robinson (2008), Acemoglu et al. (2010), Padró i Miquel (2007), Acemoglu et al. (2013b)). We contribute to this literature by showing how the dynamics of populist policies create incentives for institutional capture.

The rest of the article is organized as follows. Section (2) introduces the model. Section (3) analyzes the equilibria of the model. (4) concludes.

\section{Model}

Consider an infinite horizon game with three players: a populist leader $(P)$, a non-populist leader $(N P)$, and a (representative) voter. The voter can elect either $P$ or $N P$ to office. Per period voter utility is a function of output $g$ of the economy, $u(g), u^{\prime}(g)>0$. The voter has discount factor $\beta \in[0,1]$, so overall voter utility is $U=\sum_{t=0}^{\infty} \beta^{t} u(g)$.

Politicians only value the rent from office $R$. They have discount factor $\beta \in[0,1]$, so politician utility is $V=\sum_{t=0}^{\infty} \beta^{t} x_{t} R$, where $x_{t}$ takes value 1 if the politician is in power in period $t$, and 0 otherwise. The politician in power receives rent $R$ from office.

The economy can be in three different states: 'normal' $(\bar{g})$, in a 'boom' $(\hat{g})$, or in a 'bust' $(\check{g}): \hat{g}>\bar{g}>\check{g}$. If the economy is in a boom, in the next period there will be bust. In the period after the bust, the economy goes back to normal. When the economy is in state $g$, the voter receives utility $u(g)$.

As in Herrera et al. (2014), we focus on a specific strategic behavior by politicians, in our case the decision about institutional capture. We thus consider the dynamic profiles of output by the two politicians as a function of their intrinsic characterics. The two leaders differ in two dimensions. First, the populist leader is more likely to experience a boom once in office. ${ }^{5}$ Booms are artificial, however, in that they increase output in one period at the expense of the future. Such booms and busts can be considered a consequence of the incapacity of populist governments to implement sound economic policies. For simplicity we assume that the probability of the populist experiencing a boom is 1, while the probability of the non-populist experiencing a boom is 0 . Absent a boom, the economy remains in a normal state.

Second, the populist leader is less competent than the non-populist. Therefore, if there is a bust, the populist in power delivers utility $u(\check{g})$ to the voter, while a non-populist in power delivers utility $u(\lambda \check{g}), \lambda>1$, and

\footnotetext{
${ }^{5}$ In Herrera et al. (2014) a populist politician is denoted as bad politician.
} 
$\lambda \check{g}<\bar{g}$ : the non-populist partially, but not entirely alleviates the boom induced by the populist.

At the beginning of the game, the voter chooses to elect one of the two leaders. At the beginning of the next period, the leader in power has the option of choosing to seize control of domestic institutions at cost $c>0$. If she does so, the captured institutions ensure the re-election of the incumbent: otherwise, the voter makes a free choice based on her utility function.

In order to be more general, we abstract from the particular method by which captured institutions ensure re-election, but common examples could include the media, electoral institutions, courts, or other important elements of democracies which can influence the outcome of elections. The cost of capture measures the resilience of institutions to capture: the harder it is for an incumbent to bend institutions to her will, the higher $c$ will be. ${ }^{6}$ This cost may be material or reputational. For simplicity, capture is assumed to last only one period.

We define

$$
\begin{gathered}
\hat{u}=u(\hat{g}), \\
\bar{u}=u(\bar{g}), \\
\underline{\bar{u}}=u(\lambda \check{g}), \\
\check{u}=u(\check{g}),
\end{gathered}
$$

where $\underline{\bar{u}}$ and $\check{u}$ are respectively the utilities delivered by the the non-populist and the populist in the bust.

Thus, the following inequalities hold:

$$
\hat{u}>\bar{u}>\underline{\bar{u}}>\check{u} .
$$

We focus on the case where:

$$
2 \bar{u}>\hat{u}+\check{u} .
$$

Inequality (1) implies that an extremely patient voter, $\beta=1$, will prefer the non-populist to the populist when the populist will be in power for both a boom and a bust. If this inequality is not satisfied, for every vector of parameters $(R, c, \beta)$ the voter will elect the populist in the boom period, and so the solution is straightforward.

We assume that if a politician is indifferent between capture and no capture, she does not capture institutions: if a voter is indifferent between the

\footnotetext{
${ }^{6}$ Checks and balances, the rule of law, media pluralism, freedom of speech, the level of corruption of public officials and other factors may all affect resilience to capture. See, for example, Acemoglu et al. (2013b), Prat and Stromberg (2013) and Hillman (2004).
} 
two politicians, she chooses the non-populist. These assumptions do not affect the results.

\section{Results}

We focus on pure strategy Markov perfect equilibria (MPE) of the game, which map the current state of the game (reflected in payoffs) to strategies, such that the strategies form a subgame perfect equilibrium. As a first step, let us consider the incentives of each leader to capture institutions. We define here some notation that is useful in the equilibrium analysis.

We define $\bar{y}_{N P} \in\{0,1\}$ as the choice of capture by politician $N P$ after delivering $\bar{u}$, where 0 stands for no-capture, and 1 for capture; $\check{y}_{N P} \in\{0,1\}$ as the choice of capture by politician $N P$ after delivering $\underline{\underline{u}} ; \hat{y}_{P} \in\{0,1\}$ as the choice of capture by politician $P$ after delivering $\hat{u}$; and $\check{y}_{P} \in\{0,1\}$ as the choice of capture by politician $P$ after delivering $\check{u}$.

Let us consider the utility of the voter from electing $N P$ or $P$ at the beginning of the game, noting that the voter faces an identical stage game in every period not following a populist boom. The utility from electing the non-populist is the sum of the immediate utility $\bar{u}$ the voter gets, modified by the possibility she might not get a free choice in the subsequent period.

$$
V(N P)=\bar{u}+\beta \bar{y}_{N P} V(N P)+\beta\left(1-\bar{y}_{N P}\right) \max \{V(P), V(N P)\} .
$$

If institutions are captured $\bar{y}_{N P}$ takes value 1 . The voter re-elects the nonpopulist and receives $V(N P)$. If institutions are not captured, she elects the politician that maximizes her utility.

The value for the voter from electing a non-populist is computed similarly, though the period after the boom will involve different per-period utilities (because of the bust). Hence, the voter can receive $V(P)$ or $V(N P)$ only every other period.

$$
\begin{array}{r}
V(P)=\hat{u}+\beta \hat{y}_{P}\left[\check{u}+\beta \check{y}_{P} V(P)+\beta\left(1-\check{y}_{P}\right) \max \{V(P), V(N P)\}\right]+ \\
\beta\left(1-\hat{y}_{P}\right) \max \left\{\underline{\bar{u}}+\beta \check{y}_{N P} V(N P)+\beta\left(1-\check{y}_{N P}\right) \max \{V(P), V(N P)\},\right. \\
\left.\check{u}+\beta \check{y}_{P} V(P)+\beta\left(1-\check{y}_{P}\right) \max \{V(P), V(N P)\}\right\} .
\end{array}
$$

The value of electing the populist is based on the utility from the boom and the utility from the subsequent period, which depends on whether the populist leader captures institutions in order to retain power. 


\subsection{Institutional Capture}

Politicians consider institutional capture when they fear they will not be re-elected. If they are confident of re-election, then incurring the cost of capturing institutions is unnecessary.

If the cost of capture $c$ is lower than the per-period rent from office $R$, then incumbents will capture institutions whenever voters would otherwise elect their opponent. If, in contrast, the cost of capture is higher than the rent from office, then it is worthwhile for incumbents to incur the cost to capture institutions only if doing so prevents their loss of power in multiple periods, and they value the future sufficiently for that loss to outweigh the immediate cost of capture. As we show below, however, this does not occur in equilibrium, and so if $c \geq R$ neither politician will capture institutions.

We first analyze choices when $c<R$. Note that a limited set of groups of subgame exist, based on the possible continuations of the subgame and available strategies. We consider each group of subgames in turn.

First, let us consider a subgame in which the populist is in power and a bust has just occurred, meaning electing a populist will lead to a new boom. The populist has the option to pursue institutional capture. She will capture institutions if in this period the voter will elect $N P$, which is the case if $V(N P) \geq V(P)$. Notice that, for a politician to be in power, she must have been elected by a voter unaffected by institutional capture at some point in the previous history of the game (because politicians cannot capture institutions until they are elected). Hence, to be in power at the beginning of period $t$, there must be a period $s<t$, such that an uninfluenced voter has cast her vote for $P$, which can happen only if $V(P)>V(N P)$. Thus, if $P$ has been elected at some point, she does not need to capture institutions after delivering a bust, because the voter will elect her in the same period, even with no capture. Hence, if $V(N P) \geq V(P), \check{y}_{P}=1$ is part of a Markov perfect equilibrium, but will not be on the equilibrium path of the game. Intuitively, a populist need not capture institutions after a bust because if she is in a position to do so, it must be that voters already prefer electing populists when doing so initiates a boom.

Second, let us consider a subgame in which the non-populist is in power after delivering $\underline{\bar{u}}$, which means she was elected after the boom of the populist. The non-populist knows that at the some point in the previous history an uninfluenced voter has elected the populist, which means $V(P)>V(N P)$. Hence, the voter will elect the populist again in order to have the boom. Therefore, if $V(P)>V(N P)$, a non-populist in power after delivering $\underline{\bar{u}}$ will capture institutions. As we will see below, however, this is not on the equilibrium path. 
Third, let us consider a subgame starting in period $t$ in which the populist is in power after a boom. This means that $V(P)>V(N P)$. She will capture institutions if an uninfluenced voter would otherwise elect $N P$ in period $t$. The voter knows that, if she elects $N P$ in $t$, she will get $\underline{u}$, but $N P$ will capture institutions. Hence, an uninfluenced voter would vote for $N P$ after the populist's boom, if

$$
\underline{\bar{u}}+\beta V(N P) \geq \check{u}+\beta V(P) .
$$

If inequality (2) is satisfied, the voter would elect a non-populist after the boom phase of the populist, and for this reason the populist captures institutions. If instead (2) is not satisfied, the populist in power after the boom does not capture institutions, because the voter would elect her anyway, which is the case when the voter prefers suffering the bust instead of electing a nonpopulist who will capture institutions and inhibit a subsequent boom. In both cases the voter who elects $P$ once will elect her again, either because institutions are captured or because she willingly does so. Hence, while $N P$ would capture institutions after delivering $\underline{\underline{u}}$, she will not be elected after $P$. Our second group of subgames, considered above, is therefore not on the equilibrium path.

Finally, let us consider a subgame in which the non-populist is in power after delivering $\bar{u}$. The non-populist captures institutions if she fears that the voter will elect the populist, i.e. if $V(P)>V(N P)$. We have already made the point that there are no subgame equilibria belonging to the equilibrium path in which the non-populist is in power and $V(P)>V(N P)$. Hence, either the non-populist is elected but does not capture institutions, if $V(N P) \geq V(P)$, or she would capture institutions but is not elected in the first place, if $V(P)>V(N P)$. Thus capture by a non-populist is not on the equilibrium path if $c<R$.

Let us now consider the case in which the rent from office is lower than the cost of capture. Notice that in the subgame equilibria we analyzed, either the politician has an incentive to capture institutions only for one period, which is the case of $P$ after the boom, or in every period, as does $N P$ when $V(P)>V(N P)$. If the non-populist captures, she receives $R-c$ in every period: if she does not capture she receives 0 . Hence if $R \leq c$, she does not capture, because doing so would give her less utility.

Populists could have an incentive to capture institutions after the boom to avoid permanent capture by $N P$. If they did so, the voter would elect the populist again in the boom and the populist would get rent $R$ for two periods at the cost of a single capture $c$. But if $R \leq c, N P$ does not capture institutions, as above. Thus, neither the populist nor the non-populist has an incentive to capture institutions if $c>R$. 
Proposition 1 In equilibrium, a non-populist leader never captures institutions. If the cost of capturing institutions is lower than the returns from being in power $(c<R)$ and the voter prefers to elect the non-populist after a bust (inequality (2) is satisfied), the populist captures institutions in equilibrium after the boom to prevent the election of the non-populist during the bust.

\subsection{Equilibrium Voting}

We know that on the equilibrium path, the non-populist does not capture institutions. If $c<R$, the populist is re-elected during the bust, either because she captures institutions, if condition (2) is satisfied, or if (2) is not satisfied, because the voter freely chooses her, in order to avoid capture by the non-populist. If instead capture is too costly, $c \geq R$, the voter switches to the non-populist after the boom. Hence, the utility of voting for $P$ is the following:

$$
\begin{aligned}
& V(P)=\frac{\hat{u}+\beta \check{u}}{1-\beta^{2}}, \text { if } c<R, \\
& V(P)=\frac{\hat{u}+\beta \bar{u}}{1-\beta^{2}}, \text { if } c \geq R .
\end{aligned}
$$

The utility of voting for $N P$, given that $N P$ does not capture institutions, is

$$
V(N P)=\frac{\bar{u}}{1-\beta}
$$

The voter elects a populist when

$$
V(P)>V(N P) .
$$

Substituting equations (3), (4) and (5) into condition (6), it follows that the voter will elect $\mathrm{P}$ when

$$
\begin{aligned}
& \beta<\check{\beta}:=\frac{\hat{u}-\bar{u}}{\bar{u}-\check{u}}, \text { if } c<R, \\
& \beta<\bar{\beta}:=\frac{\hat{u}-\bar{u}}{\bar{u}-\underline{u}}, \text { if } c \geq R .
\end{aligned}
$$

When condition (7) holds, the voter prefers to elect $\mathrm{P}$ over $N P$. Intuitively, the less voters care about the future, the more they prefer $\mathrm{P}$ over $N P$. 
$\check{\beta}$ and $\bar{\beta}$ are thus the point at which the voter's choice switches between $P$ and $N P$, respectively for $c<R$ and $c \geq R$.

We can now check if the populist captures institutions when elected, i.e. if inequality (2) is satisfied. Two cases exist. If $\bar{u}-\underline{u} \leq \underline{\bar{u}}-\check{u}$, the first case, for every $\beta<\check{\beta}$ the populist is elected in equilibrium and captures institutions, because otherwise a voter would switch to a non-populist to avoid the bust. If $\bar{u}-\underline{\bar{u}}>\underline{\bar{u}}-\check{u}$, the second case, we observe the same equilibrium behavior for $\beta<\beta_{1}$, or $\beta_{2}<\beta<\check{\beta}$. If $\beta_{1} \leq \beta \leq \beta_{2}$, the populist is elected but does not capture institutions, as the voter would not switch to the non-populist after the boom. Thresholds $\beta_{1}$ and $\beta_{2}$ are two values respectively strictly larger than 0 and strictly lower than $\breve{\beta}$.

Intuitively, if $\beta$ is sufficiently low, the voter disregards the future, and prefers the non-populist to the populist in the bust because $\underline{\bar{u}}>\check{u}$. Thus, the populist captures. If $\beta$ is sufficiently high, the voter prefers the stream of utility given by the non-populist $(\underline{\bar{u}}+\beta V(N P))$ to the stream of utility given by the populist $(\check{u}+\beta V(P)){ }^{7}$ Only for an intermediate value of $\beta$ do the two cases differ: whether the populist captures or not depends on how high the payoff delivered by the populist in the bust is. If the payoff delivered by the non-populist in the bust is sufficiently large relative to the populist's $(\bar{u}-\underline{\bar{u}} \leq \underline{\bar{u}}-\check{u})$, a voter with an intermediate discount factor prefers the nonpopulist in the bust, triggering capture by the populist. Otherwise, the voter prefers the populist in the bust, and so the populist is re-elected without the need of capture.

In what follows, we assume that $\bar{u}-\underline{\bar{u}} \leq \underline{\bar{u}}-\check{u}$ in order to clarify the main results of the theory, but our results are robust to both cases, as shown in the appendix.

Proposition 2 (Institutional capture) If the voter discounts the future sufficiently to elect a populist and initiate a boom $(\beta<\check{\beta})$, she will elect a non-populist after the boom if she has the choice. Thus, if $c<R$, the populist is elected and captures institutions.

A proof is included in the appendix. This relationship is illustrated in Figure (1).

\footnotetext{
${ }^{7}$ Indeed, if the voter's $\beta$ is such that $V(P)>V(N P)$, but very close to the threshold $\check{\beta}$ in which $V(N P)=V(P)$, adding quantities $\underline{\bar{u}}$ to $\beta V(N P)$ and $\check{u}$ to $\beta V(P)$, considering that $\underline{\bar{u}}>\check{u}$, will imply that $\underline{\bar{u}}+\beta V(N P)>\check{u}+\beta V(P)$.
} 
Figure 1: Voting and capture decisions as a function of institutional resilience and discount rates

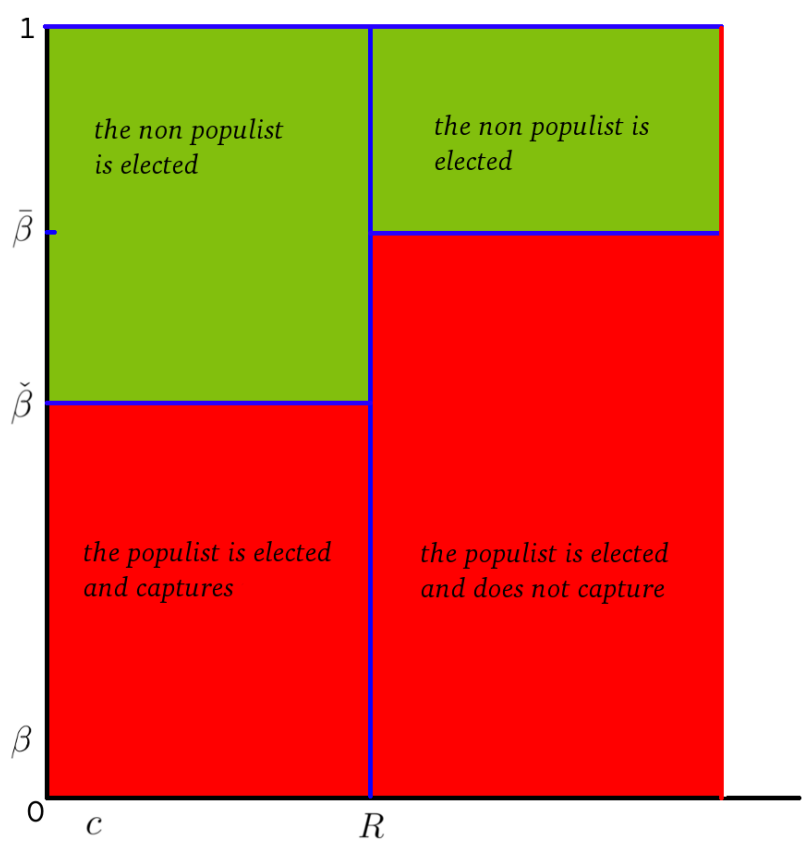

Notice that the higher the cost of capture, the larger the set of $\beta$ for which the voter will prefer a populist. If the cost of capture is sufficiently high, the populist will not capture institutions and the voter will anticipate that she will be free to switch to the non-populist in the bust phase. Hence, the appeal of electing the populist increases.

Proposition 3 (Election of populists) A populist leader is elected if voters discount the future sufficiently $(\beta<\tilde{\beta})$, or if they are somewhat patient $(\check{\beta} \leq \beta<\bar{\beta})$ but the cost of capture is so large $(c \geq R)$ that the populist will not capture institutions.

The analysis of the election of populists raises a fundamental question: when is the voter best off?

Voters are rational, and so vote to maximize their utility from their choice set in each case. However, notice that the first best for a voter would be her choice if $c \geq R$, because in that case she is free to elect in every period the politician who delivers the highest utility. In contrast, if $c<R$ voters have a more constrained choice, because they must also account for the possibility of a politician seizing control of institutions and forcing re-election. A voter 
with discount factor $\beta<\check{\beta}$ would prefer to elect the populist for a boom then shift to the non-populist in the bust, but cannot if the populist seizes institutions. Similarly, a voter with intermediate discount factor $\breve{\beta} \leq \beta<\bar{\beta}$, who in equilibrium elects the non-populist, would be better off if it was possible to have the populist in power in the boom and the non-populist in the bust. Only if a voter would actually prefer the non-populist in both booms and busts, such as when $\beta>\bar{\beta}$, is her choice set not adversely affected by the populist's capture.

Proposition 4 (Welfare analysis) If the cost of capture is low, $c<R$, populist's capture can either directly reduce voter welfare (with respect to her first best) by keeping the populist in power when the voter would prefer the non-populist, if $\beta<\check{\beta}$, or, if $\check{\beta} \leq \beta<\bar{\beta}$, distort voter's choice and induce her to elect a non-populist, again reducing her welfare with respect to her first best.

The analysis of institutional capture suggests a further implication: politicians have little incentive to maximize the resilience of institutions to capture. Indeed, let us consider a modification of the game in which either the populist or the non-populist can choose the cost of capture before the game starts. If voters discount the future highly, $\beta<\check{\beta}$, the populist would like to reduce the cost of capture to 0 because the voter will elect her anyway and she will save on the cost of capture. The non-populist will not be elected. For an intermediate discount factor, $\check{\beta}<\beta<\bar{\beta}$, the non-populist would like the cost of capture to be below $R$, in order to induce a voter with an intermediate discount factor to elect the non-populist. For a sufficiently high discount factor, $\beta>\bar{\beta}$, the voter prefers to elect $N P$ in all cases and $N P$ is indifferent between different costs of capture because she will not capture institutions anyway. The populist is not elected, thus she is indifferent between all costs of capture.

Thus, only the populist ever has an incentive to increase institutional resilience to $c \geq R$, and then only if doing so will help convince voters with intermediate discount factor, $\check{\beta}<\beta<\bar{\beta}$, that she will be unable to capture institutions and thus is worth electing.

Proposition 5 (Institutional resilience) If voters have a sufficiently high or low discount rate, then there is no incentive for politicians of either type to improve the resilience of institutions to capture. Only populists ever have an incentive to increase institutional resilience, if doing so will convince voters with an intermediate discount rate to vote for them. 


\section{Conclusion}

Our model suggests a number of conclusions. First, that absent economic shocks, goverments that provide a cycle of boom and bust payoffs have an incentive to seize control of institutions which give them the ability to influence voter decisions, while governments that provide a steady utility flow do not. Second, despite the potential for institutional capture, election of a populist government can still be rational for a voter if the cost of institutional capture is high or the voter discounts the future sufficiently. Third, that there is little incentive for both types of politicians to increase the independence of institutions.

These results are a concern for the independence of institutions worldwide, particularly since they often play an integral role in the health of a democracy. Freedom House's Freedom of the Press Report consistently finds that a relatively small share of the world has a free press, for example in 2015 , it reported that $14 \%$ of the world's population enjoyed freedom of the press. ${ }^{8}$ Clearly, many variables affect this phenomenon. We suggest, however, that short-termism on the side of voters, by electing populists who capture institutions, can be a factor influencing this outcome, as can be the limited incentives for politicians of either type to improve institutional resilience or independence when they are in power. Given the revival of populism in recent years, a better understanding of it and its effects on voters is increasingly important in understanding economic and political patterns worldwide.

Our model can be extended to show that, if specific random shocks take place during the game, also non-populists can be induced to capture instutions. Indeed, we proved that institutional capture by non-populists should not be observed in equilibrium. In subgames in which the non-populist is in power but knows the voter wants to switch to the populist, however, she will capture institutions. In the model presented, this situation is not on the equilibrium path, because if the non-populist is in power, it follows that the voter prefers her to a populist politician. If, however, a populist were to suddenly become more appealing to voters while a non-populist was in power, a non-populist would capture institutions. Economic shocks or personal scandals damaging the appeal of the non-populist could lead to this outcome. Adena et al. (2015), for example, find that radio propaganda helped the ruling Nazis to keep popular support in interwar Germany, as might be expected, but that the Weimar Republic that preceded them sometimes used the same methods. Between 1929 and 1932, in response to economic and po-

\footnotetext{
${ }^{8}$ https://freedomhouse.org/report/freedom-press/freedom-press-2015
} 
litical stresses that increased popular support for the Nazi Party, the Weimar Republic altered the previously apolitical mix of radio programming to adopt radio content that was biased against the Nazi opposition party. We can see this as an example of a non-populist government responding to an economic shock, choosing to increase its control over an institution - in this case, the media - and sway voters.

\section{Appendix}

\section{Proof of proposition (2)}

Let us consider a subgame in which the populist is in power after a boom. This means that $V(P)>V(N P)$. She will capture institutions if $R>c$ and inequality (2) is satisfied. $V(P)$ can be computed as $(\hat{u}+\beta \check{u}) /\left(1-\beta^{2}\right)$, because if $R>c$, either the populist captures institutions (if inequality (2) is satisfied) or the voter willingly elects $P$ in the bust period (if inequality (2) is not satisfied). The value of voting for $N P$ can be computed as $\bar{u} /(1-\beta)$, because if she is in power, and $V(P)>V(N P)$, she will capture institutions in every period, in order to avoid being voted out of office. Substituting the values for $V(P)$ and $V(N P)$ in inequality (2) we obtain:

$$
\begin{gathered}
\underline{\bar{u}}+\beta \frac{\bar{u}}{1-\beta} \geq \check{u}+\beta \frac{\hat{u}+\beta \check{u}}{1-\beta^{2}}, \\
\left(1-\beta^{2}\right) \underline{\bar{u}}+\beta(1+\beta) \bar{u} \geq\left(1-\beta^{2}\right) \check{u}+\beta \hat{u}+\beta^{2} \check{u}, \\
\frac{(\bar{u}-\underline{\bar{u}}) \beta^{2}-(\hat{u}-\bar{u}) \beta+\underline{u}-\check{u}}{1-\beta^{2}} \geq 0 .
\end{gathered}
$$

We can define function $f(\beta):=(\bar{u}-\underline{u}) \beta^{2}-(\hat{u}-\bar{u}) \beta+\underline{u}-\check{u}$. For $\beta \neq 1$, inequality (2) is satisfied if $f(\beta)>0 . f$ is a convex parabola in $\beta$. Notice that $f(0)>0$, and $f(1)=2 \bar{u}-(\hat{u}+\check{u})$, which is positive because $2 \bar{u}>\hat{u}+\check{u}$, as stated in condition (1). Taking the limit as $\beta \rightarrow 1$, inequality (2) can be rewritten as follows:

$$
\lim _{\beta \rightarrow 1} \frac{f(1)}{1-\beta^{2}} \geq 0 .
$$

The limit is $+\infty$ as $\beta$ tends to 1 . Thus inequality (2) is satisfied as $\beta \rightarrow 1$. Since $f$ is a convex parabola, if the set of values for $\beta$ such that $f$ is negative is non empty, it must be an interval $\left[\beta_{1}, \beta_{2}\right], 0<\beta_{1} \leq \beta_{2}<1$. If $f$ is positive on the whole interval of $\beta$ in which the populist is elected, $[0, \breve{\beta}]$, the voter would elect a non-populist after the boom phase in order to get $\underline{\bar{u}}$ instead of $\check{u}$, and for this reason the populist captures institutions. 
If $f(\check{\beta})$ is positive, it means that the interval $\left[\beta_{1}, \beta_{2}\right]$ in which the populist does not capture institutions after the boom is completely contained in either $[0, \check{\beta}]$, or in $[\check{\beta}, 1]$. Recalling equation $(7)$, function $f(\breve{\beta})$ can be expressed as follows:

$$
\begin{gathered}
(\bar{u}-\underline{\bar{u}})\left(\frac{\hat{u}-\bar{u}}{\bar{u}-\check{u}}\right)^{2}-(\hat{u}-\bar{u}) \frac{\hat{u}-\bar{u}}{\bar{u}-\check{u}}+\underline{u}-\check{u}= \\
\frac{(\bar{u}-\bar{u})(\hat{u}-\bar{u})^{2}-(\hat{u}-\bar{u})^{2}(\bar{u}-\check{u})+(\underline{\bar{u}}-\check{u})(\bar{u}-\check{u})^{2}}{(\bar{u}-\check{u})^{2}}= \\
\frac{(\bar{u}-\underline{\bar{u}}-\bar{u}+\check{u})(\hat{u}-\bar{u})^{2}+(\underline{\bar{u}}-\check{u})(\bar{u}-\check{u})^{2}}{(\bar{u}-\check{u})^{2}}= \\
\frac{\left[(\bar{u}-\check{u})^{2}-(\hat{u}-\bar{u})^{2}\right](\underline{\bar{u}}-\check{u})}{(\bar{u}-\check{u})^{2}}= \\
\frac{(2 \bar{u}-\hat{u}-\check{u})(\bar{u}-\check{u}+\hat{u}-\bar{u})(\underline{u}-\check{u})}{(\bar{u}-\check{u})^{2}} .
\end{gathered}
$$

The last expression is positive, because of condition $(1)$. Hence $f(\check{\beta})$ is positive. Moreover, if $\dot{f}(\breve{\beta})<0$, it means that the interval $\left[\beta_{1}, \beta_{2}\right]$ is contained in $[\check{\beta}, 1]$, which means that, for voter discount factors such that the populist does not capture institutions after the boom, the non-populist is elected, hence this subgame equilibrium action is not observed on the equilibrium path. The expression $\dot{f}(\check{\beta})$ is as follows:

$$
2(\bar{u}-\underline{\bar{u}}) \frac{\hat{u}-\bar{u}}{\bar{u}-\check{u}}-(\hat{u}-\bar{u})=\frac{\hat{u}-\bar{u}}{\bar{u}-\check{u}}(\bar{u}-2 \underline{u}+\check{u}) .
$$

The condition $\dot{f}(\check{\beta})<0$ is equivalent to $\bar{u}-\underline{\bar{u}}<\underline{\bar{u}}-\check{u}$. If the latter inequality is satisfied and the populist is elected in equilibrium, she captures institutions. If instead

$$
\bar{u}-\underline{\bar{u}}>\underline{\bar{u}}-\check{u},
$$

there could be a subset $\left[\beta_{1}, \beta_{2}\right]$ strictly contained in $[0, \check{\beta}]$ such that $f$ is negative. In order to investigate the existence of such interval, we analyze the conditions under which the minimum of $f$ is negative. The minimum of $f$ is at $\beta^{*}=(\hat{u}-\bar{u}) /[2(\bar{u}-\underline{\bar{u}})] . f\left(\beta^{*}\right)$ is negative if

$$
\begin{gathered}
(\bar{u}-\underline{\bar{u}})\left(\frac{\hat{u}-\bar{u}}{2(\bar{u}-\underline{\bar{u}})}\right)^{2}-(\hat{u}-\bar{u}) \frac{\hat{u}-\bar{u}}{2(\bar{u}-\underline{\bar{u}})}+\underline{\bar{u}}-\check{u}<0, \\
\frac{(\hat{u}-\bar{u})^{2}}{4(\bar{u}-\underline{\bar{u}})}-\frac{(\hat{u}-\bar{u})^{2}}{2(\bar{u}-\underline{\bar{u}})}+\underline{\bar{u}}-\check{u}<0,
\end{gathered}
$$




$$
4[(\underline{\bar{u}}-\check{u})(\bar{u}-\underline{\bar{u}})]<(\hat{u}-\bar{u})^{2} .
$$

Hence, if inequalities (8) and (9) are both satisfied, there exists an interval $\left[\beta_{1}, \beta_{2}\right]$ such that if $\beta \in\left[\beta_{1}, \beta_{2}\right]$ the populist is elected but does not capture institutions, even if $c<R$. For $\beta<\beta_{1}$ or $\beta_{2}<\beta<\check{\beta}$, the populist is elected and captures institutions. Notice that if $\underline{u}=\check{u}$, inequalities (8) and (9) are both satisfied.

Equilibrium and comparative statics if $\bar{u}-\underline{\bar{u}}>\underline{\bar{u}}-\breve{u}$ and inequality (9) is satisfied.

If $\bar{u}-\underline{\bar{u}}>\underline{\bar{u}}-\check{u}$ and inequality (9) is satisfied, there is a set $\left[\beta_{1}, \beta_{2}\right], \beta_{2}<\check{\beta}$, such that if the voter has discount factor $\beta$ in such set, she elects the populist in the boom, and she re-elects the same politician in the bust, without the need of capture. This happens because the voter prefers suffering the populist's bust than voting for the non-populist who will capture institutions. The equivalent of Figure (1) for this case is Figure (2).

Figure 2: Voting and capture decisions as a function of institutional resilience and discount rates, if $\bar{u}-\underline{u}>\underline{\bar{u}}-\check{u}$ and inequality (9) is satisfied

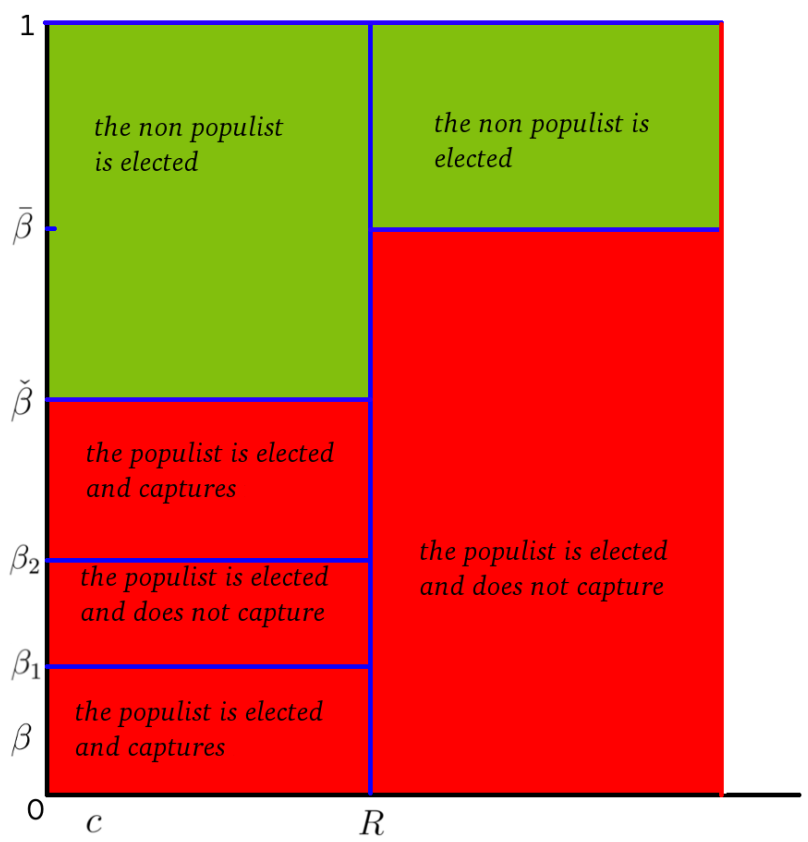

With respect to propositions (4) and (5) stated in the main analysis, there is an additional case to be considered. Proposition (4) can be complemented 
by observing that, if $\beta \in\left[\beta_{1}, \beta_{2}\right]$ and $c<R$, the voter is worse off with respect to her first best, because she elects the populist in the bust, even though she would rather have the non-populist (only) in the bust. Proposition (5) can be complemented by observing that, if $\beta \in\left[\beta_{1}, \beta_{2}\right]$, and if the populist can choose the cost $c$ at the beginning of the game, she will pick $c<R$, in order to induce the voter to elect her in the bust. The populist is indifferent between all costs in the interval $[0, R[$, because she does not capture institutions.

\section{References}

Acemoglu, D., Egorov, G., and Sonin, K. (2010). Political selection and persistence of bad governments. The Quarterly Journal of Economics, 125(4):1511-1575.

Acemoglu, D., Egorov, G., and Sonin, K. (2013a). A political theory of populism. The Quarterly Journal of Economics, 128(2):771-805.

Acemoglu, D. and Robinson, A. (2001). The colonial origins of comparative development: An empirical investigation. The American Economic Review, 91(5):1369-1401.

Acemoglu, D. and Robinson, J. A. (2008). Persistence of power, elites, and institutions. The American Economic Review, 98(1):267-293.

Acemoglu, D., Robinson, J. A., and Torvik, R. (2013b). Why do voters dismantle checks and balances? The Review of Economic Studies, 80(3):845875 .

Adena, M., Enikolopov, R., Petrova, M., Santarosa, V., and Zhuravskaya, E. (2015). Radio and the rise of the nazis in prewar germany. The Quarterly Journal of Economics, 130(4):1885-1939.

Becker, G. S. and Murphy, K. M. (1988). A theory of rational addiction. Journal of Political Economy, 96(4):675-700.

Binswanger, J. and Prüfer, J. (2012). Democracy, populism, and (un) bounded rationality. European Journal of Political Economy, 28(3):358372.

Boix, C. (1999). Setting the rules of the game: the choice of electoral systems in advanced democracies. American Political Science Review, 93(03):609624. 
Dornbusch, R. and Edwards, S. (1991). The Macroeconomics of Populism in Latin America. University of Chicago Press.

Enikolopov, R., Petrova, M., and Zhuravskaya, E. (2011). Media and political persuasion: Evidence from Russia. The American Economic Review, 101(7):3253-3285.

Falk, A., Becker, A., Dohmen, T. J., Enke, B., and Huffman, D. (2015). The nature and predictive power of preferences: Global evidence. IZA Discussion Paper.

Friedman, J. N. and Holden, R. T. (2008). Optimal gerrymandering: sometimes pack, but never crack. The American Economic Review, 98(1):113144.

Frisell, L. (2009). A theory of self-fulfilling political expectations. Journal of Public Economics, 93(5):715-720.

Herrera, H., Ordoñez, G., and Trebesch, C. (2014). Political booms, financial crises. Technical report, National Bureau of Economic Research.

Hillman, A. L. (2004). Corruption and public finance: an IMF perspective. European Journal of Political Economy, 20(4):1067-1077.

Kamenica, E. and Gentzkow, M. (2011). Bayesian persuasion. American Economic Review, 101(6):2590-2615.

Lehoucq, F. (2003). Electoral fraud: Causes, types, and consequences. Annual Review of Political Science, 6(1):233-256.

Leon, G. (2014). Strategic redistribution: the political economy of populism in Latin America. European Journal of Political Economy, 34:39-51.

McMillan, J. and Zoido, P. (2004). How to subvert democracy: Montesinos in Peru. The Journal of Economic Perspectives, 18(4):69-92.

Mejía, D. and Posada, C.-E. (2007). Populist policies in the transition to democracy. European Journal of Political Economy, 23(4):932-953.

Mény, Y. and Surel, Y. (2002). Democracies and the populist challenge. Palgrave Macmillan UK.

Mudde, C. (2004). The populist zeitgeist. Government and Opposition, $39(4): 542-563$. 
Padró i Miquel, G. (2007). The control of politicians in divided societies: the politics of fear. The Review of Economic Studies, 74(4):1259-1274.

Prat, A. and Stromberg, D. (2013). The political economy of mass media. In Advances in Economics and Econometrics: Volume 2, Applied Economics: Tenth World Congress, volume 50, page 135. Cambridge University Press.

Sachs, J. D. (1989). Social conflict and populist policies in Latin America. Working Paper 2897, National Bureau of Economic Research. 


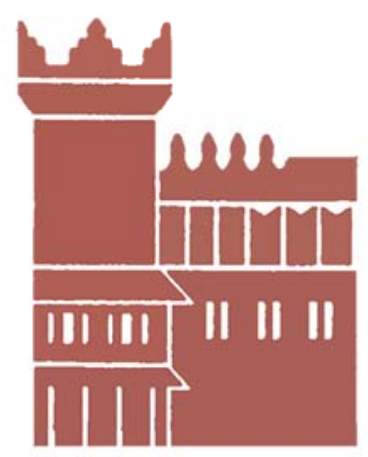

Alma Mater Studiorum - Università di Bologna DEPARTMENT OF ECONOMICS

Strada Maggiore 45

40125 Bologna - Italy

Tel. +39051 2092604

Fax +390512092664

http://www.dse.unibo.it 